\title{
Medicated Animal Feed Manufacture
}

National Cancer Institute

\section{Source}

National Cancer Institute. Medicated Animal Feed Manufacture. NCI Thesaurus. Code C84635.

Licensed facilities permitted to prepare animal food with added medications. 